\title{
Service Designers' Information Seeking: Consulting Peers versus Documenting Designs
}

Lin, Yu-Tzu; Hertzum, Morten

Published in:

Proceedings of $\mathrm{HCl}$ International 2019

DOI:

10.1007/978-3-030-23522-2_6

Publication date:

2019

Document version

Peer reviewed version

Citation for published version (APA):

Lin, Y-T., \& Hertzum, M. (2019). Service Designers' Information Seeking: Consulting Peers versus Documenting Designs. In Proceedings of HCl International 2019 (Vol. CCIS 1032, pp. 41-48). Springer. Communications in Computer and Information Science Vol. 1032 https://doi.org/10.1007/978-3-030-23522-2_6 
Proceedings of HCI International 2019 (Orlando, FL, July 26-31), Part I, CCIS vol. 1032, pp. 41-48. Springer Nature, Switzerland.

Author version. Final version at: https://doi.org/10.1007/978-3-030-23522-2 6

\title{
Service Designers' Information Seeking: Consulting Peers versus Documenting Designs
}

\author{
Yu-Tzu Lin ${ }^{1}$ and Morten Hertzum ${ }^{1}$ \\ ${ }^{1}$ University of Copenhagen, Copenhagen, Denmark \\ linyutzu@hum.ku.dk, hertzum@hum.ku.dk
}

\begin{abstract}
Service design is an information intensive activity. This study aims to investigate service designers' information behavior and understand the roles people and documents play as information sources for service designers. Ten designers were interviewed about their information seeking behavior in one service design project from its start to its completion. The interviewees were asked to describe and reflect upon their choice of information sources and their use of project documentation. Each interview lasted about 1.5 hours. The interviews were transcribed in full and the transcripts were coded with respect to design activities, information sources used, and reflections on information behavior. People served five different roles as information sources and documents served four. Documents became increasingly important sources of information as projects progressed because still more information was recorded in writing. Consistent with previous research, people play an important role because of their easy accessibility and the good quality of the information they provide. In contrast, the forwardlooking role of document creation restricts the backward-looking roles of the resulting documentation. We speculate that the consultancies suffer from poor integration across documents.
\end{abstract}

Keywords: Information seeking behavior, Information system design, Information sources.

\section{$1 \quad$ Introduction}

Service design is an information intensive activity [3, 8]. Designers need information about the users' current practices, the technological possibilities and the envisioned future [6]. Numerous information systems and prototypes have been developed to support designers in managing this information. However, designers' information needs are complex and not well-understood $[1,2,10]$. This study investigates the information behavior of service designers. We are particularly interested in what information service designers need, how they go about finding it, what role design documentation plays in this process, and in service designers' reflections on the pros and cons of their information behavior. In this study, we identify the different roles that people and documents serve as information sources and investigate how the relative importance of people and documents evolves in the course of service design projects. 


\section{Related Work}

The Wheel model aggregates multiple models of the design process and consists of iterating through four activities: analysis, design, implementation, and evaluation [4]. Information seeking is central to these activities in that analysis involves gathering information about user needs, design involves matching information about user needs with information about technological possibilities, implementation involves acquiring the detailed technology information necessary to build designs, and evaluation involves collecting information about the extent to which the current version of the design meets user needs. To support the designers' information behavior, documentation is integral to the design process. While the Wheel model presents a general design process, other models describe a process specific to service design [11, 12]. For example, the Multilevel Service Design framework [12] distinguishes among three levels: service concept, service system, and service encounter.

In general, engineers and designers use people as information sources more often than documents [7]. Bruce et al. [2] find considerable differences in the information behavior of two design teams. For example, one of the teams had little communication with people in other design teams, whereas cross-team communication was common in the other team. With respect to documents, Hertzum [5] notes that designers tend to document their work to support their own sense-making process; they are less inclined to spend time expanding their writings into documents understandable to future readers. The resulting condensed forms of writing leave most of the context unsaid. To make documents understandable to a broader audience the condensed forms of writing must be elaborated. However, such elaboration often creates frustration among the current members of a design team, who can see the elaboration as redundant [1].

Designers also tend to satisfice in their balancing of source quality against source accessibility [14]. That is, once the quality of the information source is good enough for present purposes then their choice of source is determined by ease of access, not by a continued search for the best possible source. Designers often find that people provide information of good quality. For example, Poltrock et al. [13] found that asking people was considered to yield more benefits than simply obtaining the answer to a question. They cited a software designer for saying that 'you get what's important and their analysis of it'. Conversely, documents leave it to the reader to interpret the meaning of the text and its applicability to present purposes [5]. An additional quality of people as information sources is that pertinent design knowledge, such as the design rationale, is often only held in the designers' mind and, thus, inaccessible from documents [9].

Hertzum [6] found that designers mostly obtained information from sources internal to their organization, with the exception that they mostly relied on external sources for information about the domain in which their design was to be used. In large organizations, it is sometimes recommended to look for information internally before turning to external sources because finding a good internal source provides valuable input about previous company-internal work on the issue, including the names of colleagues to consult [8]. In small and medium size organizations, external sources tend to be contacted more freely (e.g., [7]), probably because these organizations know that their size prevents them from having all the needed information internally. 


\section{$3 \quad$ Method}

We interviewed ten service designers from five design consultancies, see Table 1. In an effort to avoid mono-cultural bias, the design consultancies are from different countries. The job titles of the interviewees span design lead, UX designer, and similar profiles. We opted for interviewees at different levels of seniority but required that they had completed at least one project in the design consultancy in which they were currently employed. The interviewees constitute a convenience sample in that they were selected from the first author's network and from the contacts of the people in this network. All ten interviewees gave their written informed consent to take part in the study.

Table 1. Profile of the interviewees

\begin{tabular}{llllll}
\hline \multicolumn{1}{c}{ Country } & Gender & Seniority & Education & Project \\
\hline A & China & M & 6 years & Industrial design & Real estate \\
B & China & M & 9+ years & Architecture & Entertainment \\
C & Italy & F & 3-4 years & Interaction design & Insurance \\
D & Italy & M & 10+ years & Communication design & Insurance \\
E & Spain & F & 2-3 years & Media/interaction design & Consultancy \\
F & Spain & F & 7-8 years & Service design and innovation & Design \\
G & Taiwan & F & 1 year & Media/interaction design & Finance \\
H & Taiwan & F & 4-5 years & Industrial design & Telecom \\
I & UAE & F & 2-3 years & Industrial design & Airline \\
J & UAE & M & 10+ years & Accessories design & Airline \\
\hline
\end{tabular}

The interviews were structured into three parts. First, the interviewees described their job and design experience. At the end of this description, the interviewees were requested to select a service design project they had recently been involved in. Second, they were asked to describe what they had done in that project from its start through to its completion: What information had they needed for completing their tasks? How had they gone about finding it? Had they documented information during the project? How had they reused previously documented information? Third, the interviewees were asked to reflect on their information and documentation practices in the project they had just described: Why had they behaved this way when they needed information? What were their opinions toward documentation and using documentation? The two designers from each consultancy were not required to talk about the same project, and they all chose to talk about different projects. Each interview lasted about 1.5 hours.

The audio-recorded interviews were transcribed and coded in NVivo 11. We coded statements about three themes: the interviewees' activities, their information sources, and the reasons for their information seeking behavior. Activities were categorized into the four activities of the Wheel model [4] as well as into the three levels of the Multilevel Service Design framework [12]. Information sources were categorized into people or documents and into internal or external to the projects and consultancies. 


\section{$4 \quad$ Result}

Team members and clients were the most frequently used sources. They were consulted more often than colleagues working on other projects in the company and more often than documents. Fig. 1 shows the five roles that people played as information sources.

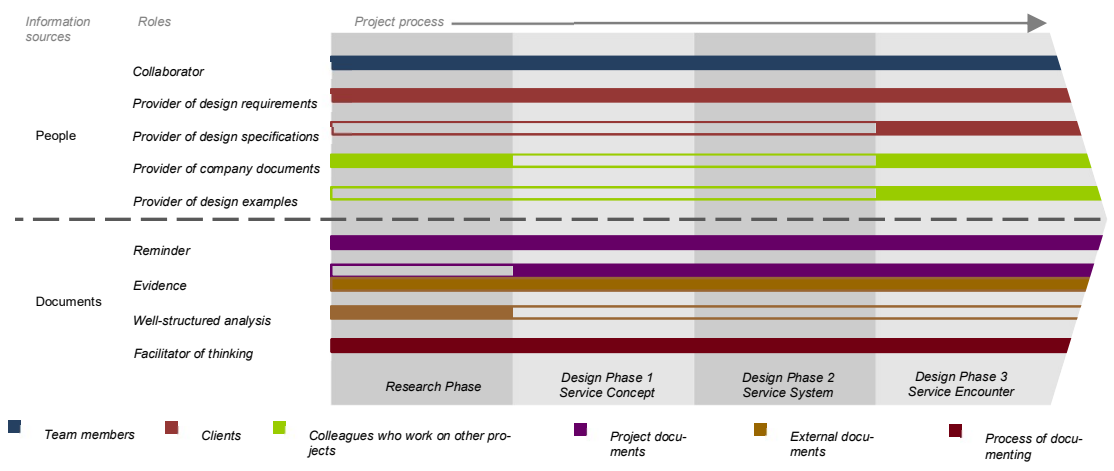

Fig. 1. The roles people and documents played in the service design projects

Team members were collaborators because all team members made design decisions together. For example, interviewee I said that she consulted her senior designers whenever she made design decisions. Sometimes designers worked by themselves, but there would always be a team discussion in each activity. Interviewee F stated that "Everybody on the team needs to participate in everything". The designers sought information from clients when they needed design requirements (e.g., user data) and design specifications (e.g., legal regulations). For example, Interviewee $\mathrm{C}$ had acquired interface specifications during meetings with her client. She received a lot of information but later learned that it was incomplete. This made the situation stressful: "So stressful, because the changes were so many. I added tons of information... I did my layout with logo and information. They were like "no, no, we cannot do this"'. The designers also sought information from colleagues who worked on other projects in the company. However, these colleagues were consulted infrequently compared to team members and clients. Designers sought information from colleagues on other projects to collect design examples and to learn about the existence of useful company documents. Interviewee $\mathrm{J}$ used colleagues as sources more often than the other interviewees. He often held workshops to collect input. The good peer-review culture in his company made the workshops an efficient way for him to collect useful information: "You end up with ten, twenty examples of similar experiences, similar applications... Ultimately, it helps me as a designer to seek advice from other people without taking too much of their time." In contrast, Interviewee B said that when he learned from colleagues on other projects, it was mainly by chance: "You learn it coincidentally when people are chatting... In our company, we are not good at this [i.e., chatting]. We all want to know what projects are currently taking place in the company, but actually we don't know, 
unless we ask." He further stated that he would ask managers for information because they knew more about the projects. However, he had not done this in the project he shared in the interview. Corresponding with his statement that managers were the best sources of cross-project information, Interviewee D (an associate creative director) shared reusable documents from other projects with his team members.

Documents served four roles in the designers' information behavior, see Fig. 1. First, the process of creating documents facilitated the interviewees in thinking about their designs. In creating project documents, the designers were visiting, interpreting, and otherwise processing the information they had available. This way the information and its implications for the project became salient to them. Often the designers did not need to go back to the documents after they had written them because the information had become present to mind. Second, documents served as reminders of project activities in which the designers had taken part. For Interviewee E it was decisive to the usefulness of a document that it was about an activity in which she had been part. If she had been then the document could provide a useful summary and reminder; if she had not been part of the activity then she doubted that the document would be sufficiently detailed for her to learn much from reading it: "If a person gives me a summary, I would not think reading it would be useful for me. However, if I experienced the process then - when I read the summary - it helps me to think of the things that happened... For me, what I need is a starting point to help me think about and recall the things that have happened." Third, documents served as well-structured analyses. For example, Interviewee B learned useful information from question-and-answer websites. Interviewee I also sought information that was structured by other people. She explained that depending on the quality of her design and the nature of her task, she would seek different types of information: "It is easier if you pick things [i.e., examples] from the ones they have filtered... I think it depends on what you want to get from it. Whether your design is already good enough or you want to make a breakthrough. [In the latter case] you have to spend more time on competitor analysis." Fourth, documents served as evidence to show the rationale for designs. The rationale could, for example, be a client requirement or a design theory. Interviewee $\mathrm{F}$ said that the design materials and design theories she sought from external documents helped her explain to clients why the team made its design decisions. Interviewee A often used project-internal documents for similar purposes. For him, detailed documents were important: "When we had some arguments with our client... we would go back to the strategy documents defined during concept design. We would tell them [the client] we did things on the basis of them [the strategies, defined together by the designer and his client]."

The designers' use of information sources evolved over the course of the design process. Early in the design process, few project documents had yet been created and information was overwhelmingly obtained from people supplemented with external documents. Later in the design process, project documents played a larger role in the designers' information seeking. This evolution coincided with a somewhat restricted approach to iteration. Already during the analysis activity the designers began to experience a reduced need for additional information. Rather than consulting more people through additional interviews, they revisited the documentation of the interviews they 
had already conducted. Notably, they did not make changes in the revisited documentation. Interviewee F explained that she saw no need for changes: "I have never seen it happen that we go back and change the research results because we discover something new... The things that you are discovering for this [i.e., for designing the screens], they are not gonna change what you have discovered in the research." Interviewee I mentioned that she maintained a document in which she kept track of whether her hypotheses were confirmed. Among the ten interviewees, this document was the only mention of a document that evolved over time. The other interviewees merely revisited documents from previous activities to obtain information from them. For example, Interviewee A returned to strategy documents to follow up on whether the design met client needs: "During concept design and detail design, we needed to constantly go back to check research files... To verify whether our design fits client needs."

\section{Discussion}

\subsection{People: Easily Accessible, High Quality, or Both}

Team members are the most frequently used internal source and clients are the most frequently used external source. When the interviewed designers consult people who are internal to their organization but external to their project, it is primarily to get links to company documents and design examples. These findings echo those of previous studies $[7,8,13]$. During projects, the interviewed designers work closely with the other team members: sharing their own points of view, listening to those of others, and making decisions together. This way, the team members are easily accessible information sources and, at the same time, knowledgeable about the context in which information is sought, thereby increasing the likelihood that they can provide context-aware answers. In contrast, clients are the authoritative source of information about design requirements and design specifications but they are less accessible. Specifically, designers will normally be unfamiliar with the client's business domain and may therefore struggle to appreciate the details of the requirements and specifications. In addition, the commercial nature of the relationship between designers and clients makes communication more delicate. Interviewee $\mathrm{C}$ illustrates that the resulting information seeking may be stressful and lead to misunderstandings in spite of the client providing lots of information. The reduced accessibility of people who are not team members increases the interviewed designers' attention to documents as information sources. For example, Interviewee B seeks information on question-and-answer websites.

\subsection{Documents: Important While They are Being Created}

The interviewed designers find that writing facilitates thinking. Thus, an important role of documents is to facilitate thinking during document creation. This role is forwardlooking. It involves processing available information to make sense of it and to become able to act competently on it. The resulting document is secondary because its creation is a means to arrive at a coherent understanding of the available information. Once the designers have arrived at this understanding it will be salient to them and available in 
their mind. Although the document is secondary to the acquired understanding, the created document serves additional roles as documentation. In these additional roles, documents provide a means for designers to look back, for example at the rationale for a design decision. It must be expected that documents are restricted in their backwardlooking roles because it is their forward-looking role that is designers' immediate motivation for creating documents. The forward-looking role is likely to produce condensed forms of writing by leaving out issues the designer already understands [1, 5]. Instead, the documents will focus selectively on the issues that are important to the designers for present purposes, often to the extent of being hard to understand for people who did not take part in the activities dealt with in the documents. For example, Interviewee $\mathrm{E}$ prefers reading documents that summarize activities in which she has taken part over reading documents that summarize design activities in which she has not taken part. The former reminds her of important issues and arguments, the latter will most likely not be of use to her because important information will be missing. Insisting that designers should elaborate their documents to make them more understandable to future readers would add considerably to the designers' workload [1].

\subsection{From People to Poorly Integrated Documents}

The designers' information behavior changes as their projects progress from the first to subsequent iterations. As the projects progress the designers increasingly revisit the documentation of previous activities rather than, for example, re-interview users. In addition, they increasingly turn to the documents previously obtained from colleagues rather than consult these colleagues anew. That is, the designers convert people sources into easily accessible documents. This transition qualifies the designers' overarching preference for people as sources. The designers' source preferences evolve with their task progress because this progress increasingly provides the designers with projectinternal documents that are tailored to the specifics of the project. Although the designers rely increasingly on documents, the documents appear to be poorly integrated. For example, Interviewee $\mathrm{F}$ mentions that discoveries made during subsequent iterations will not lead to changes in the documents from the first iteration. We speculate that the absence of such changes produces inconsistencies. One source of inconsistencies may be that the designers attend to the users' needs during the early analysis to get to grips with the design task but thereafter primarily attend to their client's needs. A primary focus on the client is unsurprising, given that the designers are consultants, but entails that the users' needs become supplementary information. Poor integration between user and client needs may limit the consultancies in the long run because it prevents them from incorporating a solid understanding of the user experience in their projects.

\section{Conclusion}

Three conclusions arise from this study. First, designers use people as information sources owing to their easy accessibility and the good quality of the answers they can provide. Second, the process of creating documents serves a forward-looking role for 
designers. This role likely yields condensed forms of writing that limit the documentary roles of the documents. Third, designers switch from primarily using people as sources during the initial project activities to making increased use of documents during subsequent project activities. However, the documents appear to be poorly integrated.

\section{References}

1. Brown JS, Duguid P (1996) The social life of documents. First Monday 1

2. Bruce H, Fidel R, Pejtersen AM, Dumais S, Grudin J, Poltrock S (2003) A comparison of the collaborative information retrieval behaviour of two design teams. The New Review of Information Behaviour Research 4:139-153

3. Gumienny R, Dow SP, Meinel C (2014) Supporting the Synthesis of Information in Design Teams. In: Proceedings of the 2014 Conference on Designing Interactive Systems. ACM, New York, NY, USA, pp 463-472

4. Helms JW, Arthur JD, Hix D, Hartson HR (2006) A field study of the Wheel-a usability engineering process model. Journal of Systems and Software 79:841-858

5. Hertzum M (1999) Six roles of documents in professionals' work. In: Bødker S, Kyng M, Schmidt K (eds) ECSCW99: Proceedings of the Sixth European Conference on Computer Supported Cooperative Work. Springer, Dordrecht, NL, pp 41-60

6. Hertzum M (2000) People as carriers of experience and sources of commitment: information seeking in a software design project. New Review of Information Behaviour Research 1:135-149

7. Hertzum M (2014) Expertise seeking: A review. Information processing \& management 50:775-795

8. Hertzum M, Pejtersen AM (2000) The information-seeking practices of engineers: searching for documents as well as for people. Information Processing \& Management 36:761778

9. Ko AJ, DeLine R, Venolia G (2007) Information Needs in Collocated Software Development Teams. In: 29th International Conference on Software Engineering (ICSE'07). pp 344-353

10. Kwasitsu L (2003) Information-seeking behavior of design, process, and manufacturing engineers. Library \& Information Science Research 25:459-476. doi: 10.1016/S07408188(03)00054-9

11. Pang S (2009) Successful service design for telecommunications: a comprehensive guide to design and implementation. John Wiley \& Sons, Hoboken, NJ

12. Patrício L, Fisk RP, Cunha JF e, Constantine L (2011) Multilevel Service Design: From Customer Value Constellation to Service Experience Blueprinting. Journal of Service Research 14:180-200. doi: 10.1177/1094670511401901

13. Poltrock S, Grudin J, Dumais S, Fidel R, Bruce H, Pejtersen AM (2003) Information seeking and sharing in design teams. In: Proceedings of the 2003 international ACM SIGGROUP conference on Supporting group work. ACM, pp 239-247

14. Simon HA (1956) Rational choice and the structure of the environment. Psychological Review 63:129-138 